\title{
Spinocerebellar Ataxia type 29 in a family of Mãori descent
}

\author{
Kathie J. Ngo ${ }^{1}$, Gemma Poke ${ }^{2}$, Katherine Neas ${ }^{2}$ and Brent L. Fogel ${ }^{1,3^{*}}$ (D)
}

\begin{abstract}
Background: Mutations in the Inositol 1,4,5-Trisphosphate Receptor Type 1 (ITPR1) gene cause spinocerebellar ataxia type 29 (SCA29), a rare congenital-onset autosomal dominant non-progressive cerebellar ataxia. The Māori, indigenous to New Zealand, are an understudied population for genetic ataxias.

Case presentation: We investigated the genetic origins of spinocerebellar ataxia in a family of Māori descent consisting of two affected sisters and their unaffected parents. Whole exome sequencing identified a pathogenic variant, p.Thr267Met, in ITPR1 in both sisters, establishing their diagnosis as SCA29.

Conclusions: We report the identification of a family of Māori descent with a mutation causing SCA29, extending the worldwide scope of this disease. Although this mutation has occurred de novo in other populations, suggesting a mutational hotspot, the children in this family inherited it from their unaffected mother who was germline mosaic.
\end{abstract}

Keywords: Cerebellar Ataxia, Spinocerebellar Ataxia, SCA29, Neurogenetics, Gait disorders/ataxia, Māori, Genetic testing

\section{Introduction}

The autosomal dominant spinocerebellar ataxias (SCAs) are a heterogeneous group of neurodegenerative disorders that cause cerebellar ataxia and degeneration of the cerebellum and brainstem. These genetic diseases have nearly 50 known subtypes characterized with extracerebellar central nervous system manifestations varying by specific genetic type [1]. Spinocerebellar ataxia type 29 (SCA29) is a rare congenital-onset autosomal dominant non-progressive cerebellar ataxia caused by mutations in the inositol 1,4,5-triphosphate receptor type 1 (ITPR1) gene characterized by early-onset hypotonia, gross motor delay, and mild cognitive impairment [2-6]. Distinct mutations in the same gene are also associated with SCA type 15 and Gillespie syndrome [1, 4].

The Mãori are the indigenous people of New Zealand, currently representing approximately $15 \%$ of the total population of the country (http://worldpopulationreview.

\footnotetext{
* Correspondence: bfogel@ucla.edu

${ }^{1}$ Program in Neurogenetics, Department of Neurology, David Geffen School of Medicine, University of California Los Angeles, 695 Charles E. Young Drive South, Gonda Room 6554, Los Angeles, CA 90095, USA

${ }^{3}$ Department of Human Genetics, David Geffen School of Medicine,

University of California Los Angeles, Los Angeles, CA 90095, USA

Full list of author information is available at the end of the article
}

com/countries/new-zealand/). To date, there is limited genomic information from this population publically available, and no comprehensive analysis of spinocerebellar ataxia causes has yet been performed. Here, we describe the genetic analysis of two siblings in a family of Māori descent presenting with congenital-onset nonprogressive ataxia by whole exome sequencing (WES).

\section{Case report}

The Institutional Review Board of UCLA approved all methods for this study. The family was identified during routine clinical evaluation in their native country of New Zealand. The affected sisters (Fig. 1) exhibited nonprogressive ataxia with onset from early infancy. The oldest sister was observed to have early delated motor milestones and first walked with crutches at age 7 years. Speech was also delayed with first word at age 5.5 years. By school age, learning difficulties were noted and formal assessment of IQ was 54. Neurological examination as an adult in her mid-forties was notable for strabismus, horizontal nystagmus, and hypermetric saccades to the left with hypometric saccades to the right (saccades were mildly misdirected). Speech exhibited a scanning dysarthria. Motor and sensory systems were intact although tone was decreased and there was a mild tremor. Limb

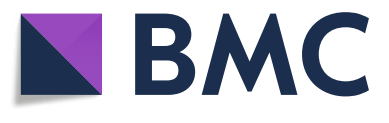

(c) The Author(s). 2019 Open Access This article is distributed under the terms of the Creative Commons Attribution 4.0 International License (http://creativecommons.org/licenses/by/4.0/), which permits unrestricted use, distribution, and reproduction in any medium, provided you give appropriate credit to the original author(s) and the source, provide a link to the Creative Commons license, and indicate if changes were made. The Creative Commons Public Domain Dedication waiver (http://creativecommons.org/publicdomain/zero/1.0/) applies to the data made available in this article, unless otherwise stated. 


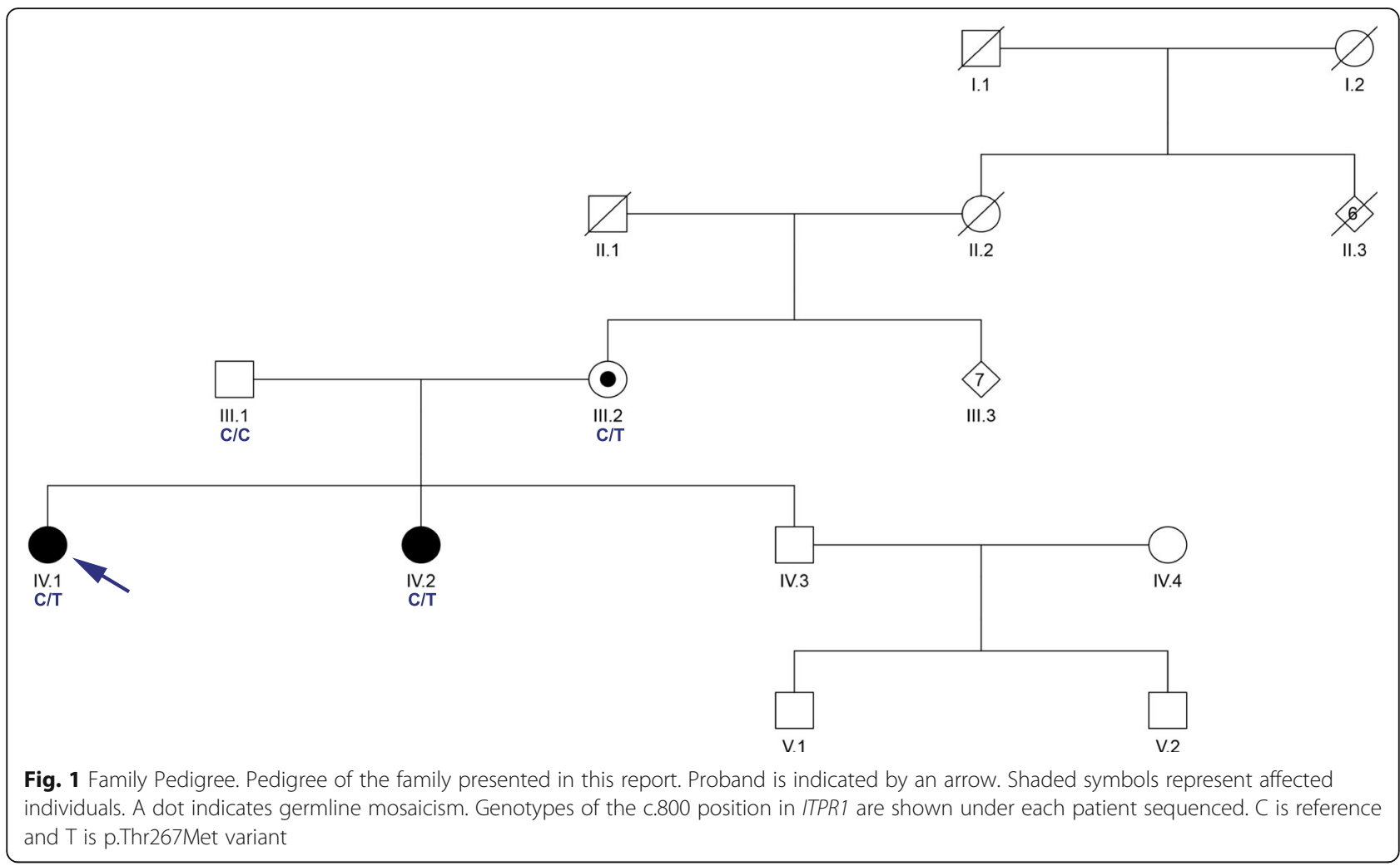

and gait ataxia were present. MRI of the brain showed atrophy of the cerebellum. The younger sister also had early delated motor milestones and first walked with crutches at age 3.5 years. Speech was also delayed with first word at age 3 years. By school age, mild learning difficulties were noted as well and IQ was measured at 73. Neurological examination as an adult in her early-forties was similar to that her sister. MRI of the brain was not performed.

\section{Diagnostic evaluation}

The family received comprehensive clinical evaluations for acquired causes of ataxia [7] and, after genetic counseling, provided written informed consent for participation in this research study. The two affected sisters tested negative for common genetic ataxias (SCA1, SCA2, SCA3, SCA6, SCA7, and SCA36). Genomic investigation for causes of spinocerebellar ataxia was performed using whole exome sequencing (WES) on all four members of the family (Fig. 1). The Nextera Rapid Capture Exome Kit (Illumina, San Diego, CA) was used to prepare the genomic DNA (gDNA) libraries. gDNA libraries were sequenced on the HiSeq 2500 sequencer in the rapid-run mode (Illumina, San Diego, CA) as 107-bp paired-end reads. Burrows-Wheeler Aligner (BWA) [8] was used to align sequencing data to the hs $37 \mathrm{~d} 5$ reference and SAMtools [9] was used to post-process the alignment data. Picard Tools (https://broadinstitute. github.io/picard/) was used to compute sequence alignment statistics and marked duplicate reads. Variants were called based on the Broad Institute's Genome Analysis Toolkit (GATK) version 3 best practices [10, 11]. Family relationships were confirmed by the relatedness algorithm from VCFtools [12]. Variants were annotated with VarSeq (Golden Helix, Inc., Bozeman, MT, www. goldenhelix.com). Variants were classified based off the American College of Medical Genetics and Genomics (ACMG) guidelines [13].

Exome sequencing identified a pathogenic variant in the ITPR1 gene present in both affected sisters. The ITPR1 variant (hg19:chr3:4687357C > T, p.Thr267Met) was previously reported as occurring de novo or sporadically [3-5] and is not present in the ExAC (exac.broadinstitute.org) or gnomAD (gnomad.broadinstitute.org) public databases of human variation. In HEK293 cells [5] and in $\mathrm{IP}_{3} \mathrm{R}$ triple knockout HeLa cells [6], the p.Thr267Met variant showed reduced IP3-induced $\mathrm{Ca}^{2+}$ release suggesting it is a loss of function mutation. Although observed in multiple families [3-5], this variant has not previously been reported as inherited through the germline. WES in our data indicated that the variant was present at low level $(2 / 242$ reads) in the unaffected mother suggesting she is germline mosaic for the variant.

\section{Discussion and conclusions}

There is little published information about genomic variation in the New Zealand Māori population and the 
prevalence of spinocerebellar ataxia in this population has not been fully studied. To date, there have been 6 reported families with Māori ancestry and spinocerebellar ataxia [14-16]. Thus far, patients have been reported with cerebellar ataxia, neuropathy, and vestibular areflexia syndrome (CANVAS) [14], hereditary spastic paraplegia type 7 [15], and autosomal recessive spastic ataxia of Charlevoix-Saguenay [16]. Mutation of the ITPR1 gene is associated with two distinct ataxic phenotypes, a progressive adult-onset form characterized primarily by gait and limb ataxia, termed Spinocerebellar Ataxia Type 15 (SCA15), and a congenital non-progressive form associated with intellectual disability (SCA29) $[1,4]$. Here, we provide the first report of SCA29 in a family of Māori ancestry originating from New Zealand. The identified p.Thr267Met mutation was germline inherited from the unaffected Māori mother who is mosaic. The observation of this same variant occurring in multiple families of different ethnic origin, including now the Māori population of New Zealand, suggests this site may be a mutational hotspot within ITPR1. This is supported by a recent study that identified this variant as part of a rare cluster of missense mutations found within the ITPR1 gene [17]. Our findings expand the prevalence and underlying genetic etiology of SCA29. Given the absence of ataxia in other members of the large extended maternal family, we speculate that this mutation occurred within the mother during her early development, resulting in the presence of the mutation in the germline and at a low level in the blood and perhaps other tissues, but sparing her of the neurological phenotype. We have previously observed parental mosaicism in other SCA29 families, both maternally (p.Gly2506Arg) [4] and paternally (p.Arg269Trp, unpublished observation), suggesting that it may be clinically informative to assess the parents of a child with SCA29 for mosaicism to aid in appropriate genetic and reproductive counseling.

\section{Abbreviations}

ACMG: American College of Medical Genetics and Genomics; BWA: BurrowsWheeler Aligner; GATK: Genome Analysis Toolkit; gDNA: Genomic DNA; ITPR1: Inositol 1,4,5-Trisphosphate Receptor Type 1; SCA: Spinocerebellar Ataxia; SCA29: Spinocerebellar Ataxia Type 29; WES: Whole Exome Sequencing

\section{Acknowledgements}

The authors wish to thank the patients and their family for their contributions to this study. The authors also thank Jessica Rexach, MD, PhD, and UCLA Neuroscience Genomics Core (UNGC) of the University of California at Los Angeles for technical assistance.

\section{Authors' contributions}

$\mathrm{GP}, \mathrm{KN}$, and BLF contributed to the conception and design of the research project and KNN was responsible for its execution. GP and KN were responsible for collection of the clinical data, samples, and/or managed patient care. KJN conducted all bioinformatics analysis. KJN and BLF wrote the manuscript and all authors were responsible for its review and critique. All authors read and approved the final manuscript.

\section{Funding}

This work was supported in part by the National Institute for Neurological Disorders and Stroke (grant R01NS082094 to Dr. Fogel), and the National Ataxia Foundation (Young Investigator Award to Dr. Fogel). The research described was supported by the National Institutes of Health/National Center for Advancing Translational Science UCLA Clinical and Translational Science Institute grant UL1TR000124. Dr. Fogel acknowledges the support through donations to the University of California by the Rochester Ataxia Foundation.

\section{Availability of data and materials}

The datasets generated and/or analyzed during the current study are not publicly available as they could compromise the anonymity of the subject but specific data elements may be available from the corresponding author on reasonable request.

\section{Ethics approval and consent to participate}

The Institutional Review Board of UCLA approved all methods for this study. After genetic counseling, the family provided written informed consent for participation in this research study.

\section{Consent for publication}

Not applicable.

\section{Competing interests}

The authors report no competing interests.

\section{Author details}

${ }^{1}$ Program in Neurogenetics, Department of Neurology, David Geffen School of Medicine, University of California Los Angeles, 695 Charles E. Young Drive South, Gonda Room 6554, Los Angeles, CA 90095, USA. ${ }^{2}$ Genetic Health Service NZ, Wellington, New Zealand. 'Department of Human Genetics, David Geffen School of Medicine, University of California Los Angeles, Los Angeles, CA 90095, USA.

Received: 10 August 2019 Accepted: 26 September 2019

Published online: 12 October 2019

\section{References}

1. Mundwiler A, Shakkottai VG. Autosomal-dominant cerebellar ataxias. Handb Clin Neurol. 2018;147:173-85.

2. Dudding TE, Friend K, Schofield PW, Lee S, Wilkinson IA, Richards RI. Autosomal dominant congenital non-progressive ataxia overlaps with the SCA15 locus. Neurology. 2004;63(12):2288-92.

3. Sasaki M, Ohba C, lai M, Hirabayashi S, Osaka H, Hiraide T, et al. Sporadic infantile-onset spinocerebellar ataxia caused by missense mutations of the inositol 1,4,5-triphosphate receptor type 1 gene. J Neurol. 2015;262(5):1278-84.

4. Zambonin JL, Bellomo A, Ben-Pazi H, Everman DB, Frazer LM, Geraghty MT, et al. Spinocerebellar ataxia type 29 due to mutations in ITPR1: a case series and review of this emerging congenital ataxia. Orphanet J Rare Dis. 2017; 12(1):121.

5. Synofzik M, Helbig KL, Harmuth F, Deconinck T, Tanpaiboon P, Sun B, et al. De novo ITPR1 variants are a recurrent cause of early-onset ataxia, acting via loss of channel function. Eur J Hum Genet. 2018;26(11):1623-34.

6. Ando $H$, Hirose M, Mikoshiba K. Aberrant IP3 receptor activities revealed by comprehensive analysis of pathological mutations causing spinocerebellar ataxia 29. Proc Natl Acad Sci U S A. 2018;115(48):12259-64.

7. Fogel BL, Lee H, Deignan JL, Strom SP, Kantarci S, Wang X, et al. Exome sequencing in the clinical diagnosis of sporadic or familial cerebellar ataxia. JAMA Neurol. 2014;71(10):1237-46.

8. Li H, Durbin R. Fast and accurate short read alignment with burrowswheeler transform. Bioinformatics. 2009;25(14):1754-60.

9. Li H, Handsaker B, Wysoker A, Fennell T, Ruan J, Homer N, et al. The sequence alignment/map format and SAMtools. Bioinformatics. 2009; 25(16):2078-9.

10. DePristo MA, Banks E, Poplin R, Garimella KV, Maguire JR, Hartl C, et al. A framework for variation discovery and genotyping using next-generation DNA sequencing data. Nat Genet. 2011;43(5):491-8.

11. McKenna A, Hanna M, Banks E, Sivachenko A, Cibulskis K, Kernytsky A, et al. The genome analysis toolkit: a MapReduce framework for analyzing nextgeneration DNA sequencing data. Genome Res. 2010;20(9):1297-303. 
12. Danecek P, Auton A, Abecasis G, Albers CA, Banks E, DePristo MA, et al. The variant call format and VCFtools. Bioinformatics. 2011;27(15):2156-8.

13. Richards S, Aziz N, Bale S, Bick D, Das S, Gastier-Foster J, et al. Standards and guidelines for the interpretation of sequence variants: a joint consensus recommendation of the American College of Medical Genetics and Genomics and the Association for Molecular Pathology. Genet Med. 2015; 17(5):405-24.

14. Wu TY, Taylor JM, Kilfoyle DH, Smith AD, McGuinness BJ, Simpson MP, et al. Autonomic dysfunction is a major feature of cerebellar ataxia, neuropathy, vestibular areflexia 'CANVAS' syndrome. Brain. 2014;137(Pt 10):2649-56.

15. Roxburgh RH, Marquis-Nicholson R, Ashton F, George AM, Lea RA, Eccles D, et al. The p.Ala510Val mutation in the SPG7 (paraplegin) gene is the most common mutation causing adult onset neurogenetic disease in patients of British ancestry. J Neurol. 2013;260(5):1286-94.

16. Nickerson SL, Marquis-Nicholson R, Claxton K, Ashton F, Leong IU, Prosser DO, et al. SNP analysis and whole exome sequencing: their application in the analysis of a consanguineous pedigree segregating Ataxia. Microarrays (Basel). 2015;4(4):490-502

17. Geisheker MR, Heymann G, Wang T, Coe BP, Turner TN, Stessman HAF, et al. Hotspots of missense mutation identify neurodevelopmental disorder genes and functional domains. Nat Neurosci. 2017;20(8):1043-51.

\section{Publisher's Note}

Springer Nature remains neutral with regard to jurisdictional claims in published maps and institutional affiliations.

Ready to submit your research? Choose BMC and benefit from:

- fast, convenient online submission

- thorough peer review by experienced researchers in your field

- rapid publication on acceptance

- support for research data, including large and complex data types

- gold Open Access which fosters wider collaboration and increased citations

- maximum visibility for your research: over $100 \mathrm{M}$ website views per year

At $\mathrm{BMC}$, research is always in progress.

Learn more biomedcentral.com/submissions 